OPEN ACCESS

Edited by:

Ulrich Schurr

Forschungszentrum Jülich, Germany

Reviewed by:

Marco Maccaferri,

Consiglio per la Ricerca in Agricoltura e l'analisi Dell'economia Agraria

(CREA), Italy

Enrico Francia,

University of Modena and Reggio

Emilia, Italy

*Correspondence:

Shawn C. Kefauver

sckefauver@ub.edu

Specialty section:

This article was submitted to

Crop Science and Horticulture,

a section of the journal

Frontiers in Plant Science

Received: 14 June 2017 Accepted: 22 September 2017

Published: 10 October 2017

Citation

Kefauver SC, Vicente $R$,

Vergara-Díaz O,

Fernandez-Gallego JA, Kerfal S,

Lopez A, Melichar JPE, Serret

Molins MD and Araus JL (2017)

Comparative UAV and Field

Phenotyping to Assess Yield and Nitrogen Use Efficiency in Hybrid and

Conventional Barley

Front. Plant Sci. 8:1733.

doi: 10.3389/fpls.2017.01733

\section{Comparative UAV and Field Phenotyping to Assess Yield and Nitrogen Use Efficiency in Hybrid and Conventional Barley}

Shawn C. Kefauver ${ }^{1 *}$, Rubén Vicente ${ }^{1}$, Omar Vergara-Díaz ${ }^{1}$, Jose A. Fernandez-Gallego ${ }^{1}$, Samir Kerfal ${ }^{2}$, Antonio Lopez ${ }^{2}$, James P. E. Melichar ${ }^{3}$, María D. Serret Molins ${ }^{1}$ and José L. Araus ${ }^{1}$

${ }^{1}$ Integrative Crop Ecophysiology Group, Department of Evolutionary Biology, Ecology and Environmental Sciences, University of Barcelona, Barcelona, Spain, ${ }^{2}$ Syngenta España, Madrid, Spain, ${ }^{3}$ Syngenta United Kingdom, Cambridge, United Kingdom

With the commercialization and increasing availability of Unmanned Aerial Vehicles (UAVs) multiple rotor copters have expanded rapidly in plant phenotyping studies with their ability to provide clear, high resolution images. As such, the traditional bottleneck of plant phenotyping has shifted from data collection to data processing. Fortunately, the necessarily controlled and repetitive design of plant phenotyping allows for the development of semi-automatic computer processing tools that may sufficiently reduce the time spent in data extraction. Here we present a comparison of UAV and field based high throughput plant phenotyping (HTPP) using the free, open-source image analysis software FIJI (Fiji is just ImageJ) using RGB (conventional digital cameras), multispectral and thermal aerial imagery in combination with a matching suite of ground sensors in a study of two hybrids and one conventional barely variety with ten different nitrogen treatments, combining different fertilization levels and application schedules. A detailed correlation network for physiological traits and exploration of the data comparing between treatments and varieties provided insights into crop performance under different management scenarios. Multivariate regression models explained $77.8,71.6$, and $82.7 \%$ of the variance in yield from aerial, ground, and combined data sets, respectively.

\section{Keywords: hybrid barley, Hordeum vulgare, nitrogen, vegetation index, UAV, RGB, multispectral, thermal}

\section{INTRODUCTION}

Global nitrogen fertilizer use is expected to exceed 200 million tons in the next year and continue to increase at $1.8 \%$ per year (FAO et al., 2015). The estimated increase in fertilizer use by $22.4 \%$ globally over the last 10 years (2004-2014) differs from an increase of $14.3 \%$ at the European level, where there is stronger and growing presence of precision agriculture management practices (Food and Agriculture Organization of the United Nations, 2017), but still demonstrates a growing demand for increased yields and an upwards trend in intensity of agricultural practices. Strikingly, this increase in fertilizer application only corresponded to barley (Hordeum vulgare) yield increases of 9.3 and $10.6 \%$ at the global and European scales, respectively. For barley, the fourth global grain in terms of production (FAO et al., 2015), this represents only 5.7 and 3.3\% increases in nitrogen use efficiency (NUE) over a period of 10 years, approximately 
half of which is attributed to improved management practices (Raun and Johnson, 1999). Given global barley production at 144.6 million tons annually, improvements in NUE represent significant savings that may enable production to meet future demand and increase profits (Raun and Johnson, 1999). Barley NUE is estimated to have been improved by nearly $26 \%$ over the past 100 years of active breeding in developed countries, with little signs of impediment, but active phenotyping toward NUE has declined since the Green Revolution in favor or maximum yield under optimum conditions (Raun and Johnson, 1999; Rajala et al., 2017). With previously estimated NUEs of 42 and $29 \%$ between developed and developing countries, much of this may be attributed to management practices such as variable rate $\mathrm{N}$ applications based on precision agriculture technology (Anbessa and Juskiw, 2012); however, improved NUE related to cultivars and hybrid selection has long been focused on top yield with $\mathrm{N}$ fertilizer intentionally removed from the study to focus on other selection criteria (Raun and Johnson, 1999; Hirel et al., 2007). Though some previous studies have covered NUE and yield differences between two-row and six-row barley varieties (Le Gouis, 1992; Papastylianou, 1995; Le Gouis et al., 1999; Frégeau-Reid et al., 2001; del Moral et al., 2003; Arisnabarreta and Miralles, 2008), hybrid barley may represent an alternative not only in terms of higher yield but also of improved growth and NUE (Gorny and Sodkiewicz, 2001; Kostadinova et al., 2016); however, to date there are no studies that we know of aimed at proving the effectiveness of remote sensing techniques as phenotyping tools for assessing the higher performance of hybrid barley in terms of growth, grain yield and NUE.

New techniques in high throughput plant phenotyping (HTPP) can provide key assistance in gathering data in support of assessing key crop physiological traits for breeding selection programs, including quantifying the physiological condition of crops, prediction of yield pre-harvest, and the heritability of traits such as increased resources use efficiencies (Furbank and Tester, 2011; Cabrera-Bosquet et al., 2012; Fiorani and Schurr, 2013; Araus and Cairns, 2014; Araus et al., 2014). In the past these techniques, applied to field phenotyping, have focused largely on the improvement in efficiency in time and cost of gathering the most important data, which remained still fairly time consuming due to the need for numerous replicates and varietal comparisons in traditional phenotyping studies. Technological advancements have been more focused on the use of robotics and automated processing of replicates and crosses in controlled laboratory conditions (Hawkesford and Lorence, 2017) and with large, expensive field machinery (Virlet et al., 2017); however, recent technological

\footnotetext{
Abbreviations: ARI2, anthocyanin reflectance index 2; CRI2, carotenoid reflectance index 2; CSI, crop senescence index; EVI, enhanced vegetation index; GA, relative green area; GGA, relative greener area; GY, grain yield; HTPP, high throughput plant phenotyping; MCARI, modified chlorophyll absorption ratio index; NDVI, normalized difference vegetation index; NG, number of grains per area; NUE, nitrogen use efficiency; OSAVI, optimized soil-adjusted vegetation index; PRI, photochemical reflectance index; RDVI, renormalized difference vegetation index; RGB, red-green-blue; SAVI, soil adjusted vegetation index; TCARI, transformed chlorophyll absorption ratio index; TGW, thousand grain weight; UAV, unmanned aerial vehicle; VIs, vegetation indices; WBI, water band index.
}

advancements in Unmanned Aerial Vehicles, UAVs, toward more stable and affordable research platforms and sensor engineering (lighter sensors with higher spatial and spectral resolution) have brought the capacity for increasing automation in a wider range of field HTPP conditions and budgets (Kefauver et al., 2015; Zhou et al., 2015; Vergara-Diaz et al., 2016).

In traditional plant breeding and phenotyping studies, the measurement of objective traits relevant for plant breeding needs to be acquired as efficiently possible to achieve statistical confidence (Montes et al., 2007; White et al., 2012; Fiorani and Schurr, 2013; Araus and Cairns, 2014). To this aim, the very high resolution and inherent color calibration of commercial digital RGB (Red, Green and Blue, or visible light) may provide fast quality image-based data acquisition (Fiorani et al., 2012; Akkaynak et al., 2014). Through not scientifically designed sensors, commercial RGB cameras include rigorous factory color calibration that enables their use for extensive scientific capacity, considering that it is in the visible where plant pigments related to photosynthesis capture light-color quality is inherently tied to photosynthesis. From this a specific suite of vegetation indices (VIs) were developed by Casadesús et al. (2007); Casadesús and Villegas (2014) to take advantage of transformations from the RGB to the CIElab, CIEluv, and HSB color spaces that can in effect remove artifacts of illumination variation and more accurately quantify the relative abundance of different pigments in plants at very detailed spatial resolutions. In a sense similar to traditional multispectral indices, Hunt et al. $(2011,2013)$ used RGB cameras to calculate normalized and area-based indices based on the broad band reflectance of each band, namely the Triangular Greenness Index and the Normalized Green Red Difference Index.

In this study, we compared the technical capacity of field- and UAV-based RGB and multispectral image analyses to differentiate the nitrogen related performance between two barley hybrids and a commercial line of barley that is widely cultivated in the region where the experiment was performed. While the emphasis of our study is in the performance of affordable remote sensing approaches (derived from RGB images), for comparison to these novel low-cost commercial RGB camera image analyses, a commercial scientific multispectral sensor was also mounted on the same UAV in order to compare the quality and costeffectiveness of the field data quantification with each sensor type. The multispectral sensor payload included a camera array of 11 separate spectral bands with an upwards pointing incident light sensor for simultaneous calibration to reflectance and a thermal camera. We calculated from the multispectral camera a suite of scientific spectral reflectance indices for the purposes of comparing the nitrogen use efficiency and yield component estimating capabilities of different combinations of high spatial (16 megapixel), low spectral resolution (RGB) sensors with low spatial resolution (1.3 megapixel) and moderate multispectral resolution (11 band) scientific sensors from a UAV HTPP. To further explore the benefits of high spatial resolution, the same RGB analyses conducted from the UAV data taken at a $50 \mathrm{~m}$ altitude was further compared with data acquired from an equal resolution commercial RGB digital camera at approximately $1 \mathrm{~m}$ above the canopy of each study plot. 


\section{MATERIALS AND METHODS}

\section{Plant Material and Experimental Setup}

The field trial was carried out during the 2015/2016 crop season in the Arazuri Station of the Institute of Agrifood Technologies and Infrastructures of Navarra (INTIA), located in Navarra, Spain ( $42^{\circ} 48^{\prime} \mathrm{N}, 1^{\circ} 43^{\prime} \mathrm{W}, 396 \mathrm{~m}$ a.s.l.). The climate conditions of the region represents a transition from Mediterranean to Atlantic climate, with a mean, maximum and minimum daily air temperature of $12.9^{\circ}, 18.8^{\circ}$, and $7.6^{\circ} \mathrm{C}$, respectively, average relative humidity of $75.2 \%$, and annual precipitation of $854 \mathrm{~mm}$ during 2015. Three barley (H. vulgare L.) genotypes were used in this study, one conventional two-row cultivar (Meseta), and two six-row hybrids (Jallon and Smooth). Meseta is a winter barley variety widely cultivated in Spain due to its high yield potential in most areas. Jallon and Smooth are two winter barley hybrids released by Syngenta S.A.U. using the Hyvido $^{\mathrm{TM}}$ technology. Barley seeds were planted in plots of $12 \mathrm{~m}^{2}(10 \times 1.2 \mathrm{~m})$ with 8 lines per plot separated by $15 \mathrm{~cm}$ at the recommended sowing rate for each variety on November 16, 2015. Initially, 10 different $\mathrm{N}$ fertilization regimens were established in the trial, differentiated in application dates and doses (Table 1). A mix of urea and ammonium sulfate was applied on January 25, 2016 in the first fertilizer applications, and urea was applied in all of the subsequent fertilizer applications. The experimental design was performed in randomized blocks with three replicates per genotype and $\mathrm{N}$ treatment combination, with a total of 90 plots (Figure 1). Weeds, insect pests and diseases were controlled by the application of the recommended pesticides for the location, including Axial Pro (Syngenta) and Trimmer (tribenuron-methyl, Conquest) herbicides at the recommended doses in one single application on April 26, 2016.

Direct measurement parameters such as vegetation indices (VIs) from ground, as well as image data acquisition with the UAV for the calculation of canopy temperature and other multispectral VIs were recorded at the growth stage of booting in all plots. All the measurements were performed during the morning and early afternoon between 10:00 and 15:00 (except the canopy temperature at afternoon). Agronomic traits were determined at physiological maturity for every plot.

\section{Agronomical Traits and Vegetation Indices (VIs) from Ground}

Agronomic traits such as thousand grain weight (TGW), number of grains per area (NG) and grain yield (GY) were determined at harvest. The harvest was done with a micro-plot combine-harvester equipped with an automatic weighing system. Additionally, the agronomical NUE (aNUE) and the nitrogen partial factor productivity (NPFP) were calculated according to (Lü et al., 2012):

$$
\begin{aligned}
\text { aNUE }\left(g \text { grain } / g N_{\text {supply }}\right) & =(G Y-G Y \text { for zero } N \text { plot }) / N_{\text {supply }} \\
\operatorname{NPFP}\left(g \text { grain } / g N_{\text {supply }}\right) & =G Y \text { for } N \text { treated plot } / N_{\text {supply }}
\end{aligned}
$$

Normalized Difference Vegetation Index (NDVI) was evaluated with an active sensor hand-held portable spectroradiometer (GreenSeeker, NTech Industries, Ukiah, CA, USA) by passing
TABLE 1 | N treatments and application dates supplied during the life cycle of

\begin{tabular}{|c|c|c|c|c|c|c|c|c|c|}
\hline References & $\begin{array}{c}\mathrm{N} \\
\text { supply }\end{array}$ & & Pre-sowing & & $\begin{array}{c}\text { January } \\
\text { (emergence) }\end{array}$ & & $\begin{array}{l}\text { February } \\
\text { (tillering) }\end{array}$ & & $\begin{array}{c}\text { April } \\
\text { (booting) }\end{array}$ \\
\hline NO & 0 & $=$ & 0 & + & 0 & + & 0 & + & 0 \\
\hline $\mathrm{N} 130 \mathrm{a}$ & 130 & $=$ & 0 & + & 65 & + & 0 & + & 65 \\
\hline N130b & 130 & $=$ & 40 & + & 50 & + & 0 & + & 40 \\
\hline $\mathrm{N} 150 \mathrm{a}$ & 150 & $=$ & 0 & + & 65 & + & 0 & + & 85 \\
\hline N150b & 150 & $=$ & 40 & + & 0 & + & 110 & + & 0 \\
\hline N150c & 150 & $=$ & 40 & + & 50 & + & 0 & + & 60 \\
\hline $\mathrm{N} 170 \mathrm{a}$ & 170 & $=$ & 0 & + & 65 & + & 0 & + & 105 \\
\hline N170b & 170 & $=$ & 0 & + & 85 & + & 0 & + & 85 \\
\hline N170c & 170 & $=$ & 40 & + & 0 & + & 130 & + & 0 \\
\hline N170d & 170 & $=$ & 40 & + & 50 & + & 0 & + & 80 \\
\hline
\end{tabular}
barley plants from three genotypes (Meseta, Jallon and Smooth).

Values are expressed in $\mathrm{kg} \mathrm{ha}^{-1}$.

the sensor in the middle of each plot at a constant height of $0.5 \mathrm{~m}$ above and perpendicular to the canopy. This index is calculated from the red and near infrared (NIR) light reflected by vegetation using the following equation: (NIR - Red) / (NIR + Red). Chlorophyll content was measured in situ using a portable chlorophyll meter SPAD-502 (Minolta, Tokyo, Japan). The measurements were carried out in the central segment of the leaf lamina, using the flag leaves of 10 plants per plot selected randomly and averaged.

For each plot, one RGB picture was taken by holding the camera at $0.8-1.0 \mathrm{~m}$ above the canopy in a zenithal plane and focusing near the center of the plot. A camera Olympus E-M10 (Olympus Corporation, Tokyo, Japan) was used with a focal length of $14 \mathrm{~mm}$, shutter speed of $1 / 250$, no flash and the aperture in automatic. The pictures were saved in JPEG format with a resolution of $4608 \times 3072$ pixels. These were analyzed with the open source BreedPix 0.2 software (Casadesús et al., 2007) for the calculation of RGB indices in the canopy based on different properties of color. In this study we used five color components of potential interest as VIs: hue, saturation, intensity, lightness, $a^{*}, b^{*}, u^{*}, v^{*}$, and the relative green area (GA) and greener area (GGA) (Casadesús et al., 2007; Vergara-Diaz et al., 2015, 2016). Hue belongs to the HSI color space (Hue, Saturation, Intensity), where Hue refers to the color tint, while Saturation follows as the amount of tint (ranging from an intense color to white) and Intensity is the overall albedo or brightness of the image (ranging from black to white). With regards to the CIE-Lab and CIE-Luv color spaces (recommended by the International Commission on Illumination (CIE) for improved color chromaticity compared to HIS color space), L represents Lightness in both CIE-Lab and CIE-Luv and is similar to Intensity or overall albedo from the HIS color space, whereas $\mathrm{a}^{*}$ and $\mathrm{u}^{*}$ represent the red-green spectrum of chromaticity and $\mathrm{b}^{*}$ and $\mathrm{v}^{*}$ represent yellow-blue color spectrum. Finally, GA and GGA indicate the green biomass in the picture calculated using the Hue channel of HIS color space as it is detailed in Casadesús et al. (2007), with the latter excluding yellowish pixels that correspond to senescent leaves. Additionally, crop senescence index (CSI), which effectively 


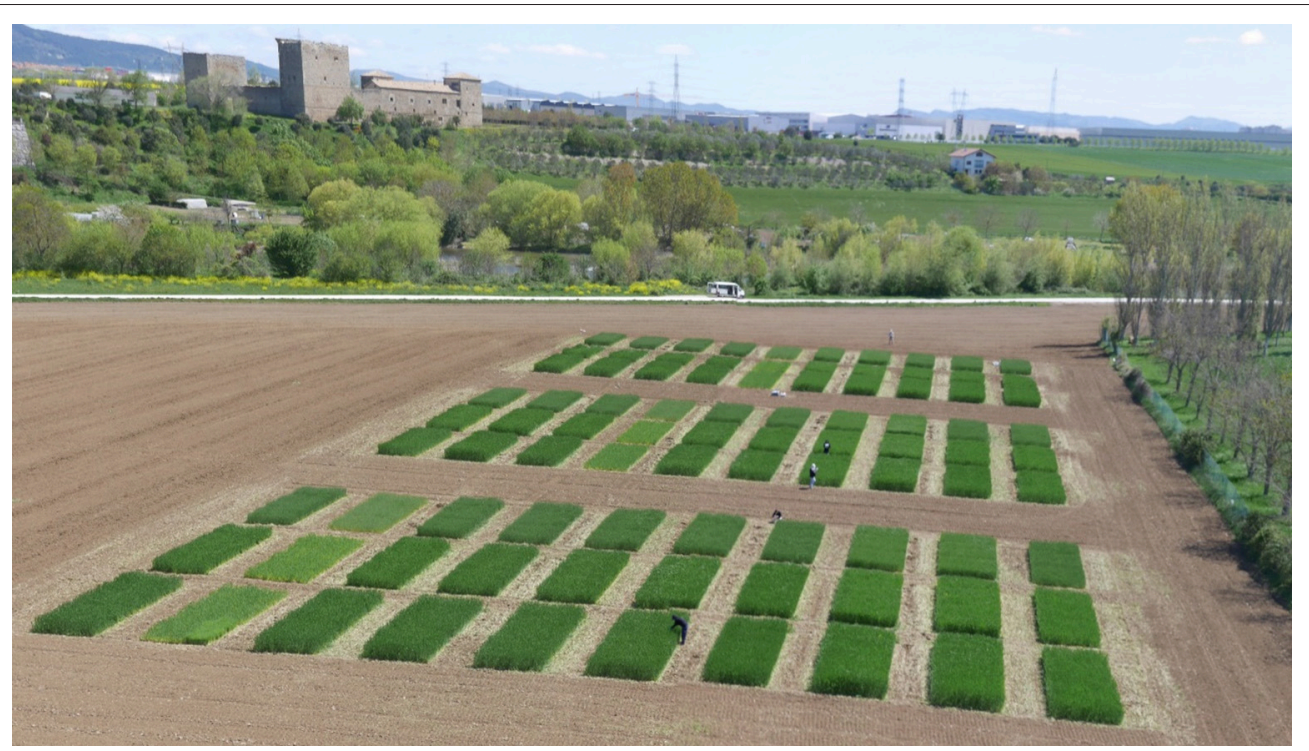

FIGURE 1 | Field experiment at Arazuri Station in Navarra (Spain) during the crop season of 2015/2016.

provides a scaled ration between yellow and green vegetation pixels in the image, was calculated in agreement with ZamanAllah et al. (2015) as follows:

$$
C S I=100 \times(G A-G G A) / G A .
$$

\section{Canopy Temperature and Vegetation Indices from Aerial Images}

All UAV aerial images were acquired on April 27, 2016 in clear sky conditions using a Mikrokopter Oktokopter 6S12 XL eight rotor UAV (HiSystems GmbH, Moomerland, Germany) flown manually at a steady velocity of approximately $5 \mathrm{~m} / \mathrm{s}$ and a pressure altimeter stabilized a.g.l. altitude of $50 \mathrm{~m}$. Image acquisition for each sensor was programmed for continuous capture for the duration of each flight with image acquisition rates of $2 \mathrm{~s}, 20 / \mathrm{s}$ and $5 \mathrm{~s}$ for the RGB, thermal and multispectral cameras, respectively, representing the maximum recommended image acquisition speed for each camera sensor system. All cameras were mounted on the same MK HiSight SLR2 camera platform with an active two servo axis gimbal to correct for UAV pitch and roll movements during flight. Different payload configurations allowed for the four image datasets to be gathered in three flights. The first included digital RGB and thermal cameras, the second flying only with the multispectral camera array, and the third flight with the thermal camera alone. Nadir image acquisition alignment accuracy was assessed and proper gimbal function was tested prior to each flight.

The RGB images were recorded starting at 11:47 am using a 16 megapixel micro 4/3 sensor Panasonic GX7 digital camera (Panasonic Corporation, Osaka, Japan) with a $20 \mathrm{~mm}$ "pancake" lens set at automatic focus with a fixed exposure time and aperture and programmed to record images continuously at intervals of $2 \mathrm{~s}$ for the duration of the flight. RGB images were imported and filtered to include only nadir images from each flight line over of the study site at the $50 \mathrm{~m}$ a.g.l. before further processing into orthomosaics. The estimated resulting pixel resolution of the RGB images was calculated at a $10 \mathrm{~mm}$ ground spatial resolution per pixel.

Canopy temperature was measured at morning ( $\mathrm{T}_{\mathrm{mor}}$, 13:01 pm) and afternoon ( $\left.\mathrm{T}_{\mathrm{aft}}, 16: 51 \mathrm{pm}\right)$ using a FLIR Tau2 640 (FLIR Systems, Nashua, NH, USA) thermal camera with a VOx uncooled microbolometer equipped with a TEAX ThermalCapture module (TEAX Technology, Wilnsdorf, Germany) for recording of full resolution thermal video ( $640 \mathrm{x}$ 520 pixels at 20 frames per second) with an estimated ground spatial resolution of $54 \mathrm{~mm}$ per pixel. The thermal images were first exported using the TEAX ThermoViewer v1.3.12 in raw 16 bit TIFF format as Kelvin * 10,000 and converted to 32 bit temperature in Celsius using a custom batch processing macro function in FIJI (Schindelin et al., 2012).

The multispectral data from the Tetracam (Tetracam, Inc., Gainesville, FL) mini MCA (Multiple Camera Array) 11 plus Incident Light Sensor (ILS) camera includes 12 individual image sensors with filters of center wavelengths and full-width half-max bandwidths of $450 \pm 40,550 \pm 10,570 \pm 10,670 \pm 10,700 \pm$ $10,720 \pm 10,780 \pm 10,780 \pm 10,840 \pm 10,860 \pm 10,900 \pm 20$, $950 \pm 40 \mathrm{~nm}$, and one sensor dedicated to real-time reflectance calibration (ILS) with a $30 \mathrm{~cm}$ fiber optic cable connected to an upwards looking box with a light diffusion plate containing 11 matching filters corresponding exactly to the 11 downwards looking sensor filters. Data acquisition was programmed for every $5 \mathrm{~s}$ for the duration of the flight at $50 \mathrm{~m}$ a.g.l., resulting in 12-band 8 bit TIFF images at 1,280 $\times 1,024$ pixels with a ground spatial resolution estimated at $27 \mathrm{~mm}$ spatial resolution per pixel. For processing, each of the resulting 12 separate images from each sensor were first aligned to correct for parallax according to the Pixel Wrench II version 1.2.2.2 Field of View (FOV) Optical Calculator and calibrated to reflectance using the PixelWrench 
II version 1.2.2.2 Index Tools MCA and ILS functions in a batch function with the provided factory calibration parameters.

The preprocessed exported images from each sensor were then combined into orthomosaics to correct for terrain and UAV flight movement by camera type for each flight using Agisoft Photoscan Professional (Agisoft LLC, St. Petersburg, Russia). Each orthomosaics image was then cut to create mini-raster images for each individual study plot using FIJI and then batch processed using custom macro functions for index calculations and simultaneous data export for each sensor, including one orthomosaic for the RGB and multispectral sensors, and morning and afternoon orthomosaics from the thermal camera.

The same RGB VIs that were calculated as described in section Agronomical traits and vegetation indices (VIs) from ground were also calculated using RGB aerial images acquired using from the UAV using the exported plot level images in the same manner as the RGB images captured in the field. The thermal data average temperature and standard deviation were exported per plot using a custom macro developed in FIJI (Schindelin et al., 2012). A suite of multispectral indices were calculated from the 11 multispectral reflectance bands of the Tetracam mini MCA $11+$ ILS as described herewith, where R indicates reflectance and the subscripts indicate wavelengths in $\mathrm{nm}$, including the NDVI calculated as Rouse et al. (1974),

$$
N D V I=\left(R_{840}-R_{670}\right) /\left(R_{840}+R_{670}\right)
$$

the Photochemical Reflectance Index (PRI) (Gamon et al., 1992),

$$
P R I=\left(R_{550}-R_{570}\right) /\left(R_{550}+R_{570}\right)
$$

Soil Adjusted Vegetation Index (SAVI) (Huete, 1988),

$$
S A V I=\left(R_{840}-R_{670}\right) /\left(R_{840}+R_{670}+L\right) \times(1+L),
$$

where L is a canopy background adjustment factor with an optimal value of $\mathrm{L}=0.5$;

the Modified Chlorophyll Absorption Ratio Index (MCARI) (Daughtry et al., 2000),

$M C A R I=\left[\left(R_{700}-R_{670}\right)-0.2 \times\left(R_{700}-R_{550}\right)\right] \times\left(R_{700} / R_{670}\right) ;$

Water Band Index (WBI) (Peñuelas et al., 1993),

$$
W B I=\left(R_{900} / R_{950}\right) ;
$$

Renormalized Difference Vegetation Index (RDVI) (Roujean and Breon, 1995),

$$
R D V I=\left(R_{840}-R_{670}\right) /\left(R_{840}+R_{670}\right)^{1 / 2} ;
$$

Enhanced Vegetation Index (EVI) (Huete et al., 2002),

$E V I=2.5 \times\left(\left(R_{840}-R_{670}\right) /\left(R_{840}+6 \times R_{670}-7.5 \times R_{450}+1\right)\right) ;$

Anthocyanin Reflectance Index 2 (ARI2) (Gitelson et al., 2001),

$$
A R I 2=R_{840} \times\left[\left(1 / R_{550}\right)-\left(1 / R_{700}\right)\right]
$$

Carotenoid Reflectance Index 2 (CRI2) (Gitelson et al., 2002),

$$
C R I 2=\left(1 / R_{550}\right)-\left(1 / R_{700}\right)
$$

Transformed Chlorophyll Absorption Ratio Index (TCARI) (Haboudane et al., 2002),

$T C A R I=3 \times\left[\left(R_{700}-R_{670}\right)-0.2 \times\left(R_{700}-R_{550}\right) \times\left(R_{700} / R_{670}\right)\right] ;$

Optimized Soil-Adjusted Vegetation Index (OSAVI) (Rondeaux et al., 1996),

$$
\text { OSAVI }=(1+0.16) \times\left(R_{780}-R_{670}\right) /\left(R_{780}+R_{670}+0.16\right) ;
$$

and the TCARI/OSAVI ratio (Rondeaux et al., 1996; Daughtry et al., 2000).

\section{Statistical Analysis}

Agronomical traits and VIs were evaluated using multivariate (PCA, principal component analysis) and univariate (ANOVA, analysis of variance) analyses with the programs CANOCO 4.5 (Microcomputer Power, Ithaca NY, USA) and SPSS 22.0 (IBM Corp., Armonk, NY, USA). ANOVA was conducted to calculate differences between genotypes (Meseta, Jallon and Smooth), nitrogen treatments (see Table 1) and their interaction. When there were differences between treatments means, they were assessed using Tukey's HSD test. The results were accepted as significant at $P<0.05$. Most of the traits were not significantly altered by the interaction genotype $\times \mathrm{N}$ treatment. Therefore, we presented in this study the significant effects for the main factors independently. A correlation matrix was generated in $\mathrm{R}$ environment for evaluating the linear relationships between all parameters analyzed. Visualization of significant correlations was performed using the software Cytoscape 3.4.0 (Shannon et al., 2003). The significance threshold for correlations between traits was set at $r>0.6$ for positive correlations and $r<-0.6$ for negative correlations, with a $P$-value $<0.001$ in both cases. The figures for the PCA were built in CanoDraw 4.0 (Microcomputer Power) and for agronomical traits and linear regressions in SigmaPlot 11.0 (Sysat Software Inc., Point Richmond, CA, USA). Stepwise regressions between grain yield and VIs were performed in SPSS 22.0 to develop prediction models for grain yield. The proportion of variance explained by each predictor was calculated in $\mathrm{R}$ environment using the package relaimpo.

\section{RESULTS}

Nitrogen use indexes as presented in Table 2 include the agronomical nitrogen use efficiency (aNUE) and $\mathrm{N}$ partial factor productivity (NPFP) according to the $10 \mathrm{~N}$ application regimens as detailed in Table $\mathbf{1}$ for the two hybrid (Jallon and Smooth) and one conventional genotype (Meseta) of the study. While the aNUE is calculated in reference to the N0 regimen yield in order to estimate the use efficiency of the fertilizer applied on top of the residual nitrogen found present in the soil, NPFP adjusts for yield in reference to the applied nitrogen supply per treatment without reference to the other treatments. There were 
TABLE 2 | Agronomical nitrogen use efficiency (NUE) and N partial factor productivity according to the $10 \mathrm{~N}$ application regimens as detailed in Table 1.

\begin{tabular}{|c|c|c|c|c|c|c|c|c|}
\hline & \multicolumn{4}{|c|}{ Agronomical NUE (g grain $\mathrm{g} \mathrm{N}^{-1}$ ) } & \multicolumn{4}{|c|}{$\mathrm{N}$ partial factor productivity (g grain $\mathrm{g} \mathrm{N}^{-1}$ ) } \\
\hline & Meseta & Jallon & Smooth & $P$ & Meseta & Jallon & Smooth & $P$ \\
\hline N130a & 20.12 & 13.89 & 22.38 & 0.057 & $46.93 \mathrm{a}$ & $46.69 \mathrm{a}$ & 57.06 b & 0.017 \\
\hline N130b & 21.69 & 19.13 & 20.91 & 0.857 & 48.51 & 51.94 & 55.58 & 0.376 \\
\hline N150a & 18.09 & 16.67 & 17.65 & 0.946 & 41.34 & 45.10 & 47.69 & 0.402 \\
\hline N150b & 17.75 & 20.44 & 20.05 & 0.381 & 40.99 a & $48.87 b$ & $50.10 \mathrm{~b}$ & 0.006 \\
\hline N150c & 20.89 & 21.11 & 23.00 & 0.855 & 44.13 & 49.54 & 53.05 & 0.171 \\
\hline $\mathrm{N} 170 \mathrm{a}$ & 17.84 & 11.97 & 18.24 & 0.053 & $38.35 \mathrm{a}$ & $37.06 \mathrm{a}$ & $44.75 \mathrm{~b}$ & 0.028 \\
\hline N170b & 18.90 & 15.50 & 16.80 & 0.479 & 39.41 & 40.58 & 43.31 & 0.381 \\
\hline N170c & 19.51 & 17.96 & 19.43 & 0.420 & $40.01 \mathrm{a}$ & $43.04 a b$ & 45.94 b & 0.009 \\
\hline N170d & 17.28 & 18.61 & 23.45 & 0.128 & $37.78 \mathrm{a}$ & $43.69 \mathrm{ab}$ & 49.96 b & 0.011 \\
\hline
\end{tabular}

NO is used for reference in the calculation of each and as such is not shown. Treatments in bold indicates $P<0.05$.

no significant differences found between the three genotypes in the aNUE calculations, there are several clear separations in NPFP between the hybrid and conventional genotypes, notably at N130a, N150b, N170c, and N170d.

A close inspection of the principal component analysis (PCA) combining the agronomical and physiological traits of the different levels and application regimens of the study trial design and the measured parameters from the UAV HTPP and field data (Figure 2) demonstrates which field methods have measured similar crop attributes and how they are related to the different genotypes and $\mathrm{N}$ levels (Figure 2A) and to the different $\mathrm{N}$ levels and application dates (Figure 2B). In both PCA's there is a clear separation on PCA axis 1 between variables associated with higher total green biomass (GA, GGA, Hue, NDVI, OSAVI) and pigment/stress (CSI, $v^{*}$, TCARI/OSAVI, PRI, ARI2). The second PCA axis appears to have separated SPAD as a leaf measurement from some of the alternatives to RGB color space that are often considered as indicators ground cover (Saturation, $\mathrm{v}^{*}$ and $\mathrm{b}^{*}$ ). In Figure 2A it appears that the lower nitrogen application levels positioned more associated with the pigment/stress plant field measurements while the higher nitrogen applications and yield are on the side of higher total green biomass. Meseta, the conventional variety, appears opposite measures of total ground cover and green biomass. In Figure 2B, again N0 is associated strongly with pigment/stress, while the rest are only slightly on the side of total biomass and more spread along the PCA axis 2, indicating differences in chlorophyll leaf concentration (SPAD) and percent ground cover. There is little difference noted between the different nitrogen application levels $\left(130-170 \mathrm{~kg} \mathrm{ha}^{-1}\right)$, with more separation between the application timings (a, b, c, d), with the largest separation between N170a and N170c.

Similar patterns are observed when comparing the different varieties in the agronomical components in Figure 3. We see significant differences in grain yield (GY) and thousand grain weight (TGW) between the three varieties, but in terms of number of grains (NG) the hybrids Smooth and Jallon are together higher in comparison to the lower NG of the Meseta. In nearly all cases, not surprisingly N0 is significant lower, but in terms of GY, only N130a and N170d show significantly different effects, while there is only slightly more separation in terms of the yield subcomponents into a total of four groups for NG and TGW. In all three comparisons, there were no separation between N130b and N170b, for example. In Figure 4, looking in greater detail at GY, we observe no interactions between genotype and the non-zero nitrogen application regimens. There were no differences at all in the conventional variety Meseta, and only two slight separations in treatments in the hybrid varieties Jallon and Smooth and more so due to fertilization regimen timing rather than quantity of fertilizer.

The full summary of the different non-destructive ground and aerial VIs presented in Table 3 demonstrates their similar capacity for quantifying the interactions between genotype and treatment. With regards to total $\mathrm{N}$ and fertilizer application timing, the physiologically based VIs are frequently able to separate genotypes or differentiate between the conventional and hybrid varieties. We also observe similar results from aerial and ground measurements, as with the high resolution RGB image analyses. However, little consistency is observed between the non-zero $\mathrm{N}$ application quantities, with somewhat more distinction made between treatments different in both nitrogen quantity and timing. For example, there were significant differences between the minimal number of applications in $\mathrm{N} 130 \mathrm{a}$ and N150a regimens and the three to four field applications in N170c and N170d treatments (NDVI, Hue, and GGA from the ground measurements; and additionally NDVI, RDVI, SAVI and OSAVI from the aerial multispectral data). All of these physiological indices are considered indicators of total green biomass, albeit from different sensors and spectral regions. The capacity for these total green biomass physiological indices to track differences in yield is further corroborated in the yield correlation network presented in Figure 5A, where yield is effectively surrounded by the same set of VIs that were capable of detecting differences related to the combination of $\mathrm{N}$ amount and timing (GA, GGA, NDVI, RDVI, SAVI, and OSAVI).

NG is also very closely correlated with GY, while TGW is not. In Figure 5B, the detailed graphs of the VIs most significantly correlated directly with GY are shown, including ground calculations of GA and GGA together $\left(r^{2} \quad 0.70\right.$ and 0.72 , respectively), ground and aerial based calculations of CSI together ( $r^{2} 0.69$ and 0.65 , respectively), SAVI and its optimized 
A

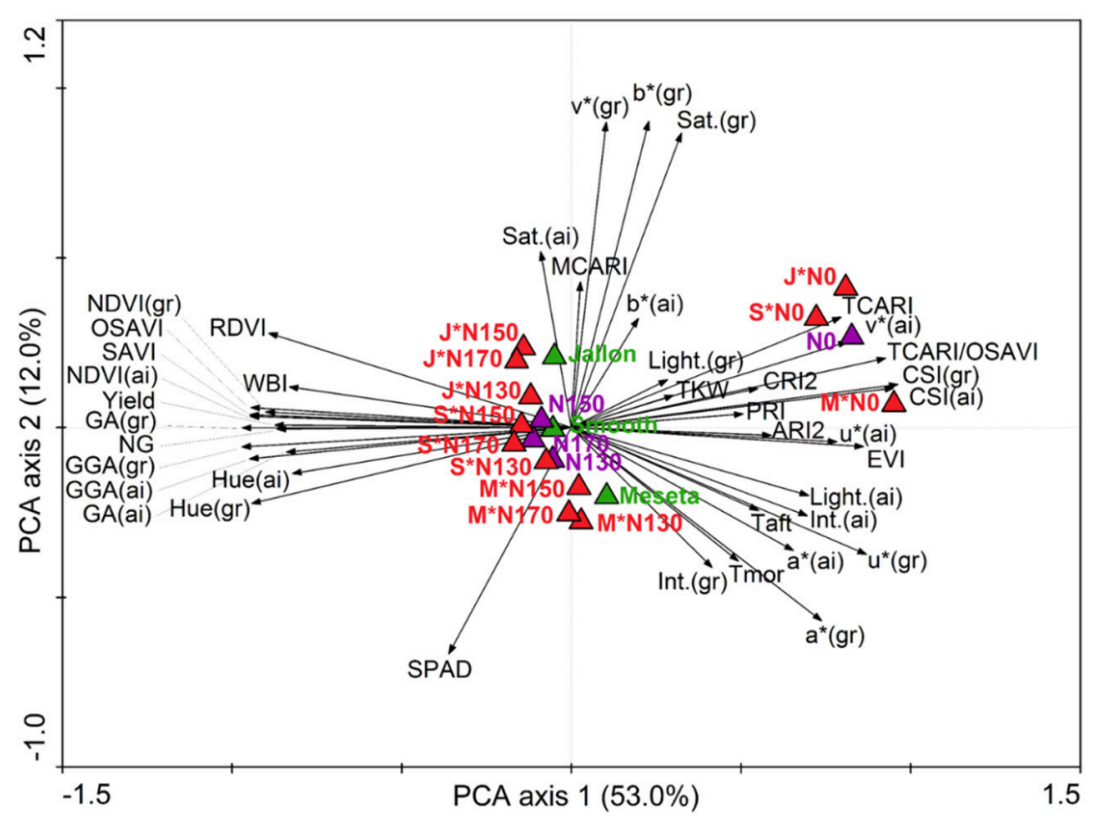

B

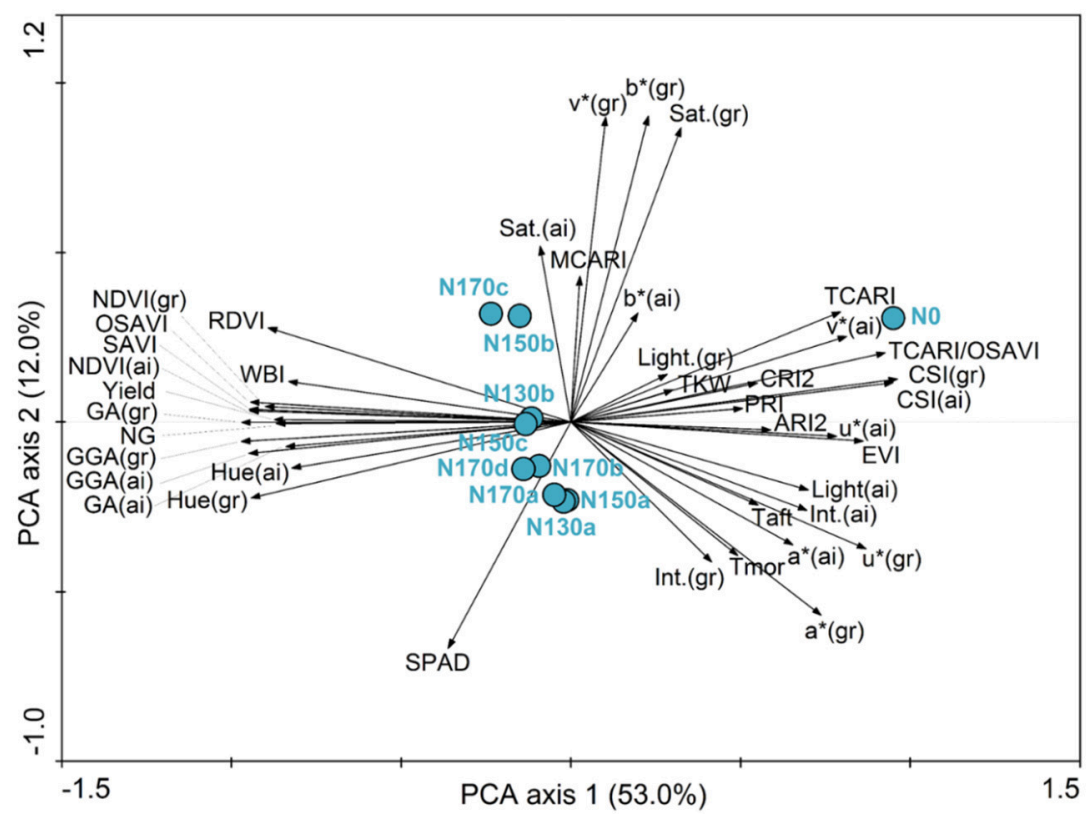

FIGURE 2 | Principal component analysis (PCA) of agronomical and physiological traits in three barley genotypes at different N levels. Arrows represent the variables and triangles the different genotypes (green), $\mathbf{N}$ levels (purple) and their interaction (red) in (A), and circles the different $\mathrm{N}$ levels and application dates in (B) according to Table 1. M, Meseta; J, Jallon; S, Smooth.

variant OSAVI together $\left(r^{2} 0.66\right.$ and 0.65 , respectively), and WBI ( $\left.r^{2} 0.68\right)$, RDVI ( $\left.r^{2} 0.66\right)$, NDVI $\left(r^{2} 0.65\right)$, and Hue $\left(r^{2}\right.$ $0.65)$ separately below. The asymptotic effects of signal saturation are observable more strongly in the correlation graphs of both NDVI and Hue, while the WBI and RDVI both appear to hold fairly linear in comparison though linear regressions were used in all cases for the sake of comparison. Morning $\left(\mathrm{T}_{\text {mor }}\right)$ and afternoon $\left(\mathrm{T}_{\mathrm{aft}}\right)$ temperature were both significantly higher for the N0 treatment compared to N150b and N170c, while only $\mathrm{T}_{\mathrm{aft}}$ provided additional separation between N0 and N130b, N150c and N170a.

In Table 4 we present multivariate linear models for estimating grain yield using different selections of nondestructive VIs as indicated using both forward and backward 

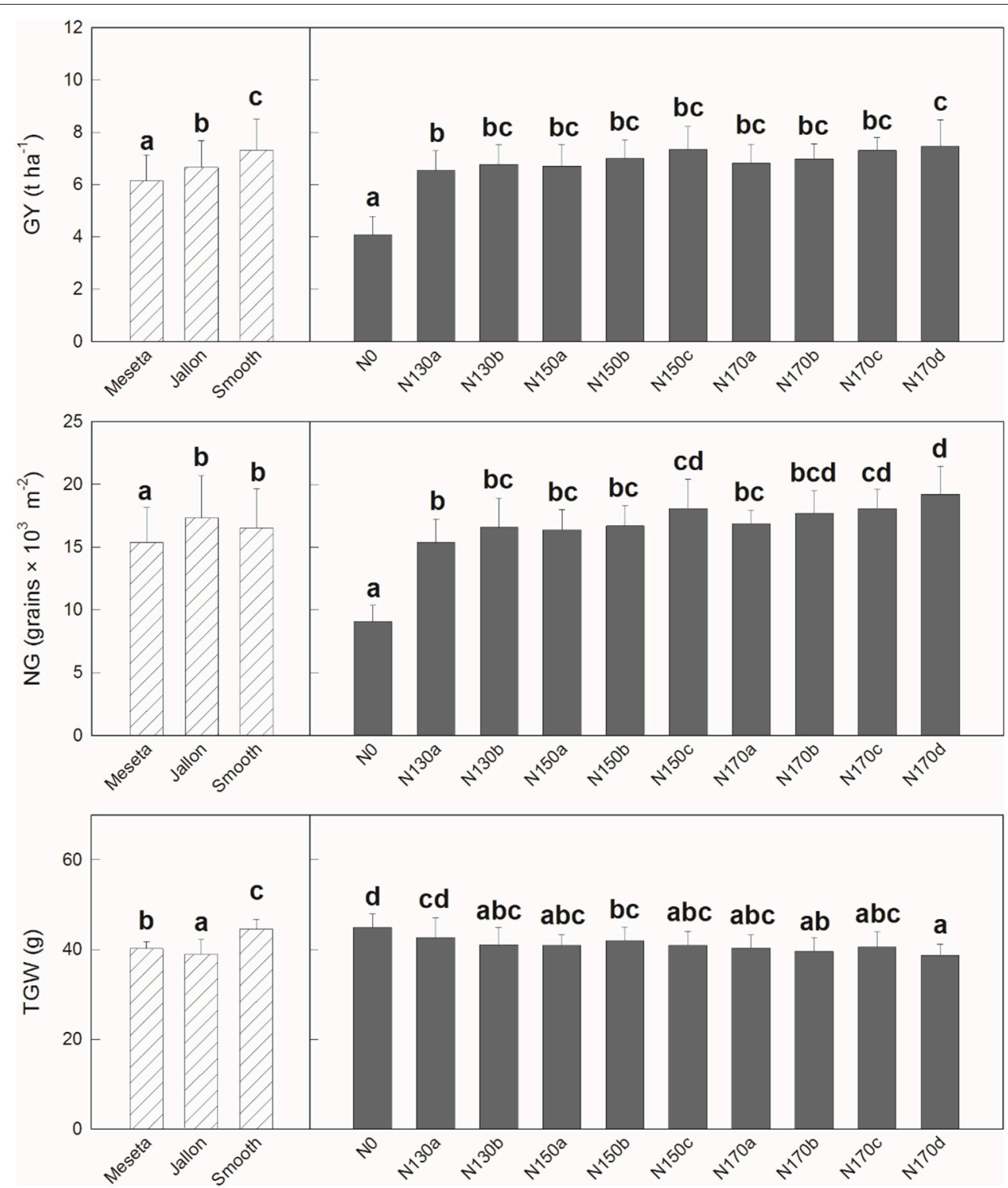

FIGURE 3 | Grain yield (GY), thousand grain weight (TGW), and number of grains per area (NG). Each value is the mean \pm SD for each genotype and nitrogen supply ( $n=30$ for genotypes and $n=9$ for $\mathrm{N}$ supplies). Bars with different letters are significantly different at $P<0.05$.

stepwise selection techniques, with a standard AIC selection criterion. We also present the proportion of variance explained by each model predictor, in terms of total variance explained by each predictor (sum equaling the total model $\mathrm{r}^{2}$ ) and the standard error of prediction (SEP). All three models presented were found to be significant at the $P<0.001$ level. Using the UAV platform for image acquisition, which allows for the use of the 11+ILS sensor multispectral camera as well as the same sensors used on the ground, explains a total of $77.8 \%$ of the variation in yield for all 90 plots across genotypes under different $\mathrm{N}$ supply regimens (total plus application timing) can be explained by the WBI and SAVI indices. In the case of ground based VIs, $71.6 \%$ of the yield may be explained by the GGA index alone. In the case of combining VIs from both aerial and ground measurements, a total of $82.7 \%$ of yield variation may be explained. In the case of the combined aerial and ground measurements, the RGB indices Hue and GGA taken from the ground level contributed nearly $50 \%$ of the final $r^{2}$-value to the multispectral VIs WBI and RDVI, with morning temperature making a minor contribution.

\section{DISCUSSION}

\section{Total $\mathbf{N}$ and N Application Regimen Timing Contributions to Yield}

Directed plant phenotyping efforts toward improving barley nitrogen use efficiency (NUE) and efficacy must take into account 

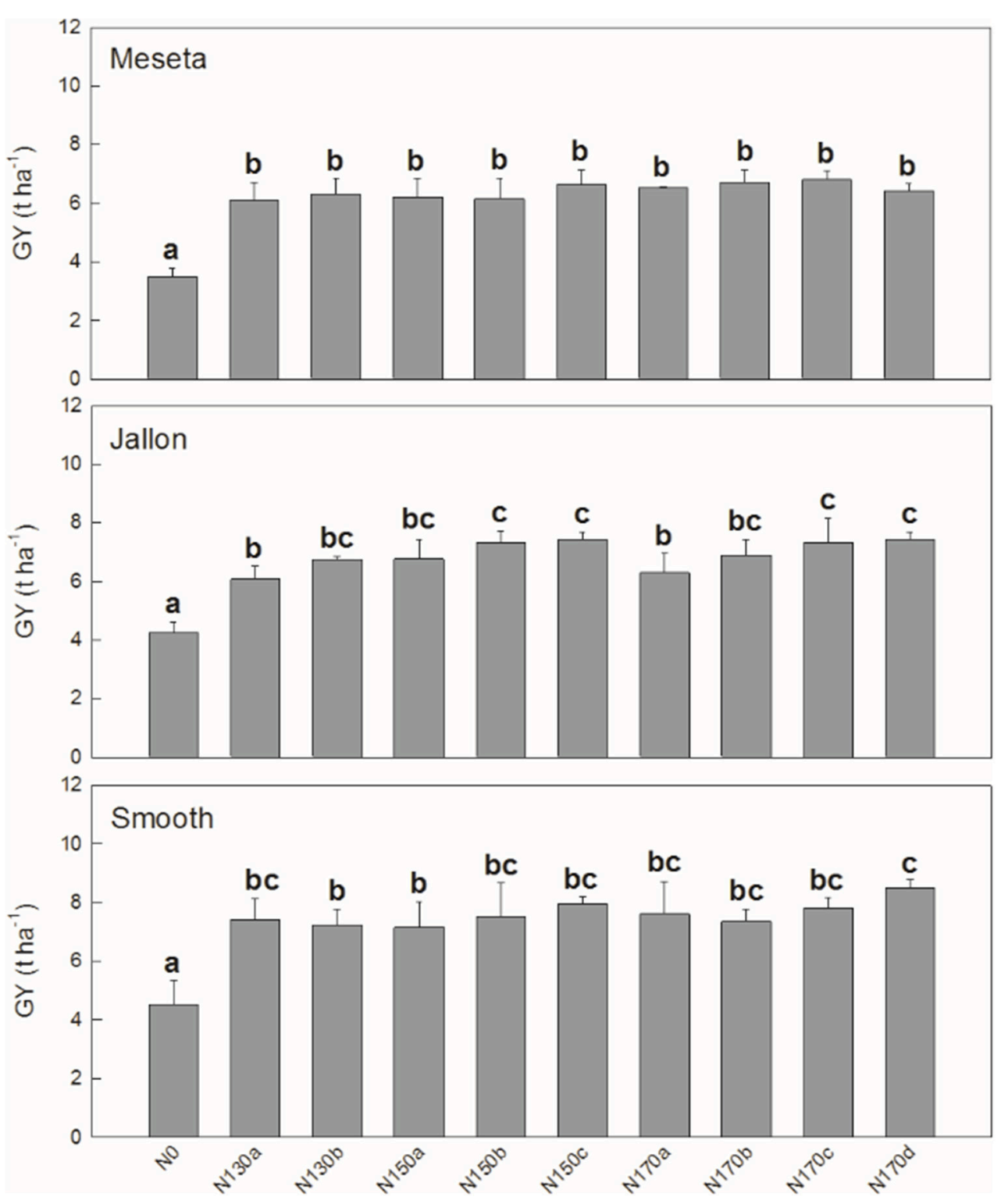

FIGURE 4 | Meseta (conventional), Jallon (hybrid), and Smooth (hybrid) barley varieties. Each value is the mean $\pm S D$ for each genotype separately for each nitrogen supply ( $n=3$ for genotype replicates and $n=9$ for $\mathrm{N}$ supplies). Bars with different letters are significantly different at $P<0.05$.

the physiological mechanisms that affect NUE, but also consider the associated economic costs of different fertilizer application regimens, namely via plant nitrogen uptake and storage capacity (Raun and Johnson, 1999; Hirel et al., 2007; Anbessa and Juskiw, 2012; Krapp, 2015; Kostadinova et al., 2016; Rajala et al., 2017). Not only the amount of fertilizer applied, but also the number and timing of these applications may contribute to specific growth stages of the crop and thus result in less or greater contribution to the final yield of the crop. In the two approximations of NUE presented in Table 2, the agronomical nitrogen use efficiency (aNUE) and $\mathrm{N}$ partial factor productivity (NPFP), we may observe some potential for error in each as an approximation of actual NUE in the case of not fully accounting for residual soil nitrogen. While there were no differences in aNUE between the hybrids (Jallon and Smooth) and the conventional genotype (Meseta), we are also able to note that the yield from both the hybrids was quite a bit higher than the conventional variety in the N0 treatment. This in of itself may be interpreted as an indication of higher NUE by the hybrids at low $\mathrm{N}$ levels, something in of itself of potential interest. Also, since $\mathrm{N} 0$ is the reference point for the other N treatments' aNUE, the higher yield of the hybrids already at N0 becomes a strong weighing factor in subsequent calculations. The separations in NPFP between the hybrid and conventional genotypes, notably at N130a, N150b, N170c, and N170d, if they may be assumed as better indicators of relative NUE between the genotypes, 


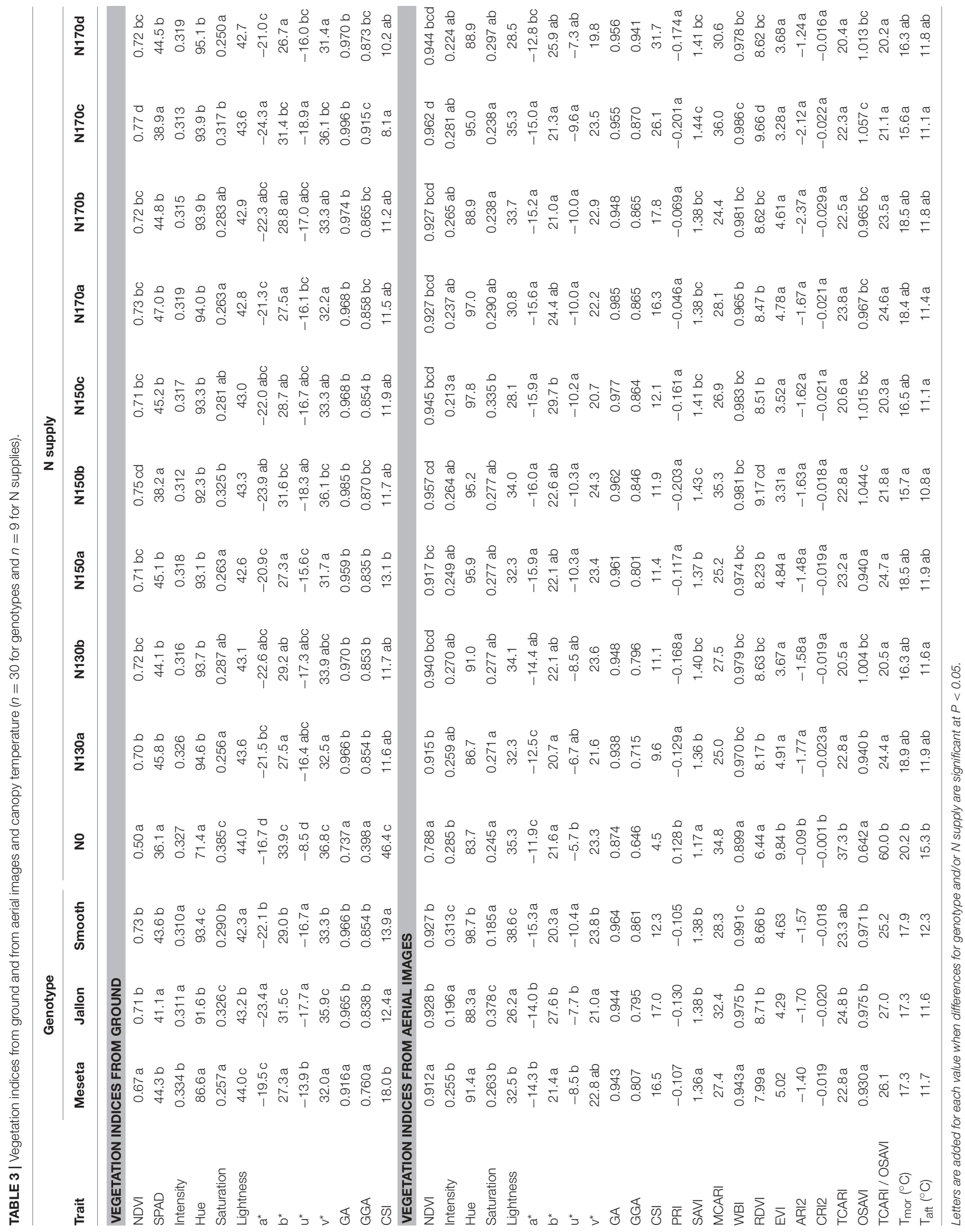




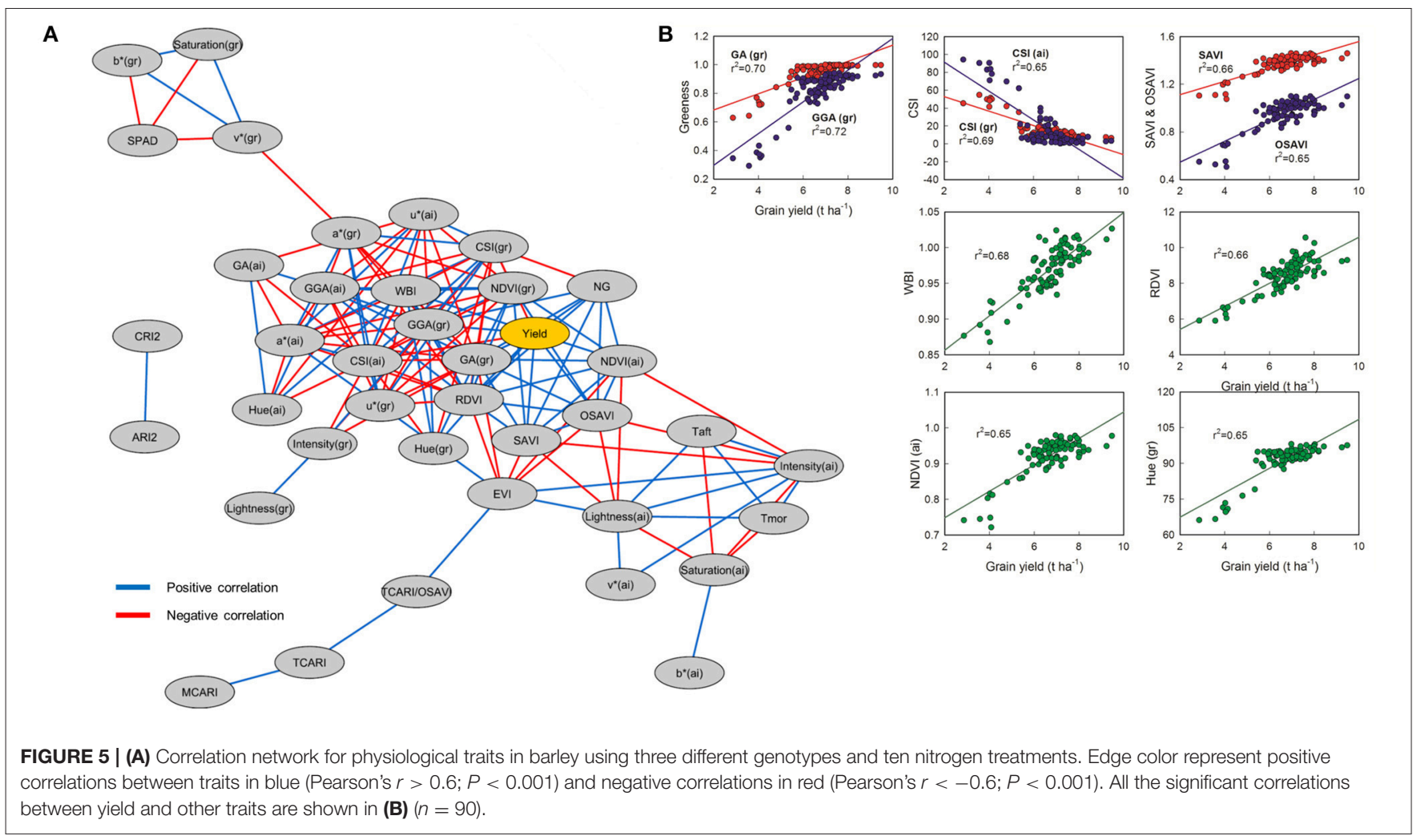

TABLE 4 | Multivariate regression models explaining grain yield variation from vegetation indices (VIs) across genotypes under different $\mathrm{N}$ supplies.

\begin{tabular}{|c|c|c|c|c|c|}
\hline Predicted parameter & Traits & Multivariate model & $r^{2}$ & SEP & $P$ \\
\hline Grain yield & $\begin{array}{l}\text { Vegetation indices } \\
\text { (from aerial images) }\end{array}$ & $\mathrm{GY}=17.32 \times \mathrm{WBI}+6.49 \times \mathrm{SAVI}-19.02$ & 0.778 & 0.555 & $<0.001$ \\
\hline \multirow[t]{2}{*}{ Grain yield } & $\begin{array}{l}\text { Vegetation indices } \\
\text { (from ground) }\end{array}$ & $\mathrm{GY}=1.41+6.46 \times \mathrm{GGA}(\mathrm{gr})$ & 0.716 & 0.625 & $<0.001$ \\
\hline & & $\begin{array}{l}\text { Proportion of variance explained by each predictor: } \\
\text { - GGA(gr) }\end{array}$ & 0.716 & & \\
\hline \multirow[t]{2}{*}{ Grain yield } & Vegetation indices (all) & $\begin{array}{l}\mathrm{GY}=15.83 \times \mathrm{WBI}+0.17 \times \text { Hue }(\mathrm{gr})-7.39 \times \mathrm{GGA}(\mathrm{gr}) \\
+0.51 \times \mathrm{RDVl}-0.48 \times \mathrm{T}_{\mathrm{mor}}-21.90\end{array}$ & 0.827 & 0.499 & $<0.001$ \\
\hline & & $\begin{array}{l}\text { Proportion of variance explained by each predictor: } \\
\text { - WBI } \\
\text { - Hue(gr) } \\
\text { - GGA(gr) } \\
\text { - RDVI } \\
\text { - Tmor }\end{array}$ & $\begin{array}{l}0.210 \\
0.197 \\
0.192 \\
0.181 \\
0.047\end{array}$ & & \\
\hline
\end{tabular}

SEP, standard error of prediction.

again serves to highlight the importance of management practice on NUE, potentially indicating more strongly the different capacities of each genotype for nitrogen uptake and storage.

Too minimal number of field applications will result in an over application of fertilizer at any one time, exceeding the crop uptake capacity and result in loss of excess fertilizer due to leaching during rain or irrigation. Similarly, temporal infrequency with long time periods between fertilizer applications may exceed the plant capacity for $\mathrm{N}$ storage and stunt growth in subsequent stages or trigger $\mathrm{N}$ mobilization in a way that lowers yield by reducing total photosynthetic biomass prior to grain filling. These concepts are supported by the first comparisons of the data presented in this study 
where indeed the only differences observed between the different non-zero nitrogen regimens are in terms of the application frequency rather than the total fertilizer application amounts. There is more separation in the PCAs presented in Figure 2B where fertilizer timing by genotype is considered compared to Figure $\mathbf{2 A}$ where only the total amount is considered. This is even more clearly supported by Figure 3 where the only differences in GY, NG, and RGW were found between the N130a regimen and the $\mathrm{N} 170 \mathrm{c}$ and/or $\mathrm{N} 170 \mathrm{~d}$ regimens, indicating that the increase in total $\mathrm{N}$ is only to be marginally effective if also increasing the frequency of application. In no instance was there any distinction between N130a and N170a, suggesting an exceedance of $\mathrm{N}$ uptake and/or storage capacity in terms of yield production.

In Figure 4, with the detailed look at the full fertilizer regimen by genotype, there is no separation at all between non-zero $\mathrm{N}$ treatments in the conventional variety Meseta. The lowest fertilization rate $\left(130 \mathrm{~kg} \mathrm{ha}^{-1}\right)$ applied in both two or three doses were sufficient to exceed the nitrogen uptake/assimilation capacity of Meseta. Therefore, tilling costs could be reduced with the application of less amounts and frequency of nitrogen fertilizer. Jallon appears to have a greater capacity for fertilizer uptake and use as evidenced by increased yield at higher fertilizer applications with increased frequency. The analysis of the application dates suggested that initial nitrogen fertilization during pre-sowing guarantee higher grain yields at 130, 150, and $170 \mathrm{~kg} \mathrm{ha}^{-1}$. This could be an advantage due to better crop establishment and initial tiller development (Baethgen et al., 1995). The lesser degree of separation between the different frequencies of application ( $a, b, c, d$ ) in Smooth compared Jallon may suggest a greater capacity for $\mathrm{N}$ storage for subsequent mobilization at critical yield contributing growth stages. For instance, average GY in Smooth was higher than in Jallon. Overall, in both barley hybrids there is a tendency to higher GY when nitrogen is applied at sowing. It may indicate that the contribution of preanthesis reserves to grain filling is crucial (Van Sanford and MacKown, 1987; Baethgen et al., 1995). These findings suggest that the rate and timing of nitrogen application depend on each genotype. Therefore, the characterization of the different nitrogen strategies in barley genotypes could be relevant to significantly reduce the costs of fertilizers and tilling and the potential ground water contamination by nitrogen leaching.

\section{Non-destructive Vegetation Indices for Ground and UAV Phenotyping}

Genotypic differences in VIs between the conventional line, Meseta, and the hybrids, Jallon and Smooth, suggest that the hybrids presented greater canopy biomass and green area, water status and delayed senescence (Table 3). These traits were correlated with GY, as indicated in the correlation network (Figure 5), which suggest that the greater canopy biomass, water status and the delayed senescence in the hybrids, especially in Smooth, were an advantage over the conventional line. The hybrids showed greater capacity for fertilizer uptake with higher GY when nitrogen is applied at sowing, as we reported above, which could have led to a higher tillering and crop canopy cover during vegetative growth as VIs indicated. In previous studies, a rapid development of wheat plants was considered a positive trait for plant performance and to avoid abiotic stresses (Bort et al., 2014; Medina et al., 2016).

From a methodological perspective on the use of UAVs for phenotyping, especially in terms of non-destructive measurements for the selection of different levels of performance by phenotype and treatment, both the high resolution RGB and the multispectral VIs presented here performed comparatively similar. Both class of VIs here managed to track the different levels of performance from each of the three barley varieties in terms of final post-harvest yield (Table 3 ) equally well as in the comparison of the final yield and yield parameters themselves (GY, NG, TGW; Figures 3, 4). This presents a case for the potential benefits of this technology for modernizing traditional plant phenotyping programs for both the improvement of throughput in terms of time and labor spent in the field as well as the amount of time that the crop must be grown before selection is possible, both of which also represent cost savings (Fiorani and Schurr, 2013; Araus and Cairns, 2014; Hawkesford and Lorence, 2017). Furthermore, the comparable performance of the relatively low cost RGB sensors, with use of appropriate methodology as applied in this study, present a viable alternative to the use of advanced scientific instruments such as the Tetracam MCA11+ILS for plant phenotyping trials and studies (Kefauver et al., 2015; Vergara-Diaz et al., 2015; Zhou et al., 2015).

Still, the use of UAVs also enables the deployment of these image analysis techniques for calculating various VIs to the realm of field phenotyping with both improved throughput (capability to cover hectares in minutes) and complete individual plot coverage of whole trials to provide a more complete capture of variability in field conditions compared to other point or subset area field measurements such as SPAD or Greenseeker NDVI (Fiorani and Schurr, 2013; Araus and Cairns, 2014; Zaman-Allah et al., 2015). On the other hand, more advanced sensor technology, such as field spectroscopy or hyperspectral imaging sensors, may offer some improvements in $\mathrm{N}$ content estimation and other relevant physiological parameters (Clevers and Kooistra, 2012; Zarco-Tejada et al., 2012; Pölönen et al., 2013; Bareth et al., 2015; Gonzalez-Dugo et al., 2015).

\section{Contributions of UAV Plant Phenotyping Platform for Improving Barley NUE and Application Regimen Efficacy}

The highest correlations with final grain yield came from the GGA and GA indices from RGB images taken at the ground level followed closely by the same indices measured from the UAV aerial platform. In the application of multivariate models and stepwise selection as presented in Table 4, GGA alone was only slightly outperformed by two multispectral indices $\left(r^{2} 0.716\right.$ vs. 0.778). This may be related to the capacity of the multispectral indices to measure plant physiological components separately, such as with the WBI and SAVI indices selected here (Huete, 1988; Gamon et al., 1992; Peñuelas et al., 1993), whereas the RGB indices most likely calculate a combination of physiological 
components or overall performance related to biomass and/or total green biomass (Casadesús et al., 2007; Casadesús and Villegas, 2014). In this sense, different multispectral indices may be more often complimentary in a multivariate model compared to the quantification provided by high resolution RGB covering only broad electromagnetic regions in the visible spectrum.

As seen in the final multivariate model combining all the VIs from the ground and the UAV, the optimal combination may be found in a selection of the best estimates overall crop performance (RDVI and GGA contributing 0.192 and 0.181 to the total model $r^{2}$ ) and some multispectral index specific to the target traits of the study, such as WBI, Hue or temperature, which may be tracking more specific traits such as pigment quality and root growth, representing traits more specific to the varying nitrogen regimens of this study (contributing 0.210, 0.197, and 0.047 to the total model $r^{2}$ ). Interesting enough the split between more general performance indices and specific indices appears to be about even, though it can be argued that the WBI in a lack of water stress conditions may also be tracking biomass more closely than actual water stress, since it is a measure of total water in the plant canopy and is thus also strongly affected by total plant biomass (Huete, 1988; Huete et al., 2002). Hue can be seen as a potential pigment quantification replacement for the multispectral pigment indices of ARI2, CRI2, MCARI, TCARI, and TCARI/OSVI, but was here found to be much more closely related to yield, which may be due to the fact that at high spatial resolution sampling, it must also contain some component of biomass as it separates out vegetation fractional cover based soil background color separation from plant photosynthetic and non-photosynthetic vegetation.

The relevance of the inclusion of both WBI and mid-morning temperature $\left(\mathrm{T}_{\text {mor }}\right)$ may even be interpreted as factors related to increased root growth that allowed for increased nutrient uptake capacities in the higher yielding hybrid varieties. Other previously discussed comparisons in terms of the difference in performance with fertilizer application timing and number of applications may also support this; however, since this study did not include specifically root measurements, that cannot be confirmed here, as it has been in other studies (Postma et al., 2014; Gioia et al., 2015). Still, as UAV and sensor technology and processing continues to advance, we may expect their contributions to high-throughput plant phenotyping to similarly increase (Hruska et al., 2012; Suomalainen et al., 2014; Gevaert et al., 2015).

\section{REFERENCES}

Akkaynak, D., Treibitz, T., Xiao, B., Gürkan, U. A., Allen, J. J., Demirci, U., et al. (2014). Use of commercial off-the-shelf digital cameras for scientific data acquisition and scene-specific color calibration. J. Opt. Soc. Am. A Opt. Image Sci. Vis. 31, 312-321. doi: 10.1364/JOSAA.31.000312

Anbessa, Y., and Juskiw, P. (2012). Review: Strategies to increase nitrogen use efficiency of spring barley. Can. J. Plant Sci. 92, 617-625. doi: 10.4141/cjps2011-207

Araus, J. L., and Cairns, J. E. (2014). Field high-throughput phenotyping: the new crop breeding frontier. Trends Plant Sci. 19, 52-61. doi: 10.1016/j.tplants.2013.09.008

\section{CONCLUSIONS}

Nitrogen management, including rate and timing, is a key factor controlling grain yield in barley genotypes. The selection of hybrids with a better plant performance compared to lines, such as greater crop canopy cover, water status and delayed senescence, could contribute to the enhancement of barley yield stability and nitrogen use efficiency. UAV platforms and associated technology including aerial platform control and stability, appropriate affordable scientific research sensors and processing software capacities have advanced sufficiently to be of use for HTPP studies in field conditions. This technology allows for the development of phenotyping selection criteria for yield under different experimental trial conditions, including but not limited to the nitrogen fertilizer regimen treatments in this study, or for the selection toward improving specific physiological capacities such as nitrogen use efficiency or nitrogen uptake or storage and remobilization capacity.

\section{AUTHOR CONTRIBUTIONS}

SCK led the writing of the manuscript and coordinated the research project and RV led the statistical analyses and figure preparation. SCK, RV, JA, and SK contributed to the majority of the critical revision of the manuscript text. SCK, RV, OV, SK, MS, and JA all contributed significantly to the field and UAV data acquisition, data processing, and experimental data interpretation. SK, AL, and JM led the design of the experimental trial, the management of the trial cultivation, and the collection of the agronomical data at harvest. All authors have revised the work for intellectual content and have contributed to and approved the final content.

\section{ACKNOWLEDGMENTS}

This study was supported by the collaborative project "Desarrollar fenotipeado de alta capacidad en la red de ensayos que la Empresa tiene distribuidos en la geografía española" between Syngenta España S.A.U. and the University of Barcelona, funded by the company. Dr. Kefauver is supported by a Juan de la Cierva "Incorporación" postdocoral research fellowship funded by the Spanish Ministry of the Economy and Competitivity (MINECO). We would also like to thank Jesús Goñi Rípodas and the staff of Arazuri Station (INTIA) for their valuable support on the field trial.

Araus, J. L., Li, J., Parry, M. A., and Wang, J. (2014). Phenotyping and other breeding approaches for a New Green Revolution. J. Integr. Plant Biol. 56, 422-424. doi: 10.1111/jipb.12202

Arisnabarreta, S., and Miralles, D. J. (2008). Critical period for grain number establishment of near isogenic lines of two-and six-rowed barley. Field Crops Res. 107, 196-202. doi: 10.1016/j.fcr.2008.02.009

Baethgen, W. E., Christianson, C. B., and Lamothe, A. G. (1995). Nitrogen fertilizer effects on growth, grain yield, and yield components of malting barley. Field Crops Res. 43, 87-99. doi: 10.1016/0378-4290(95) 00034-N

Bareth, G., Aasen, H., Bendig, J., Gnyp, M. L., Bolten, A., Jung, A., et al. (2015). Low-weight and UAV-based hyperspectral full-frame cameras for 
monitoring crops: spectral comparison with portable spectroradiometer measurements. Photogrammetrie Fernerkundung Geoinformation 2015, 69-79. doi: $10.1127 / \mathrm{pfg} / 2015 / 0256$

Bort, J., Belhaj, M., Latiri, K., Kehel, Z., and Araus, J. (2014). Comparative performance of the stable isotope signatures of carbon, nitrogen and oxygen in assessing early vigour and grain yield in durum wheat. J. Agric. Sci. 152, 408-426. doi: 10.1017/S0021859613000269

Cabrera-Bosquet, L., Crossa, J., von Zitzewitz, J., Serret, M. D., and Araus, J. L. (2012). High-throughput phenotyping and genomic selection: the frontiers of crop breeding converge. J. Integr. Plant Biol. 54, 312-320. doi: 10.1111/j.1744-7909.2012.01116.x

Casadesús, J., Kaya, Y., Bort, J., Nachit, M. M., Araus, J. L., Amor, S., et al. (2007). Using vegetation indices derived from conventional digital cameras as selection criteria for wheat breeding in water-limited environments. Ann. Appl. Biol. 150, 227-236. doi: 10.1111/j.1744-7348.2007.00116.x

Casadesús, J., and Villegas, D. (2014). Conventional digital cameras as a tool for assessing leaf area index and biomass for cereal breeding. J. Integr. Plant Biol. 56, 7-14. doi: 10.1111/jipb.12117

Clevers, J. G., and Kooistra, L. (2012). Using hyperspectral remote sensing data for retrieving canopy chlorophyll and nitrogen content. IEEE J. Sel. Top. Appl. Earth Obs. Remote Sens. 5, 574-583. doi: 10.1109/JSTARS.2011.2176468

Daughtry, C. S. T., Walthall, C. L., Kim, M. S., de Colstoun, E. B., and McMurtrey, J. E. III. (2000). Estimating corn leaf chlorophyll concentration from leaf and canopy reflectance. Remote Sens. Environ. 74, 229-239. doi: 10.1016/S0034-4257(00)00113-9

del Moral, L. F. G., del Moral, M. B. G., Molina-Cano, J. L., and Slafer, G. A. (2003). Yield stability and development in two-and six-rowed winter barleys under Mediterranean conditions. Field Crops Res. 81, 109-119. doi: 10.1016/S0378-4290(02)00215-0

FAO, IFAD, and WFP (2015). The State of Food Insecurity in the World 2015. Food and Agriculture Organization of the United Nations, Rome.

Fiorani, F., Rascher, U., Jahnke, S., and Schurr, U. (2012). Imaging plants dynamics in heterogenic environments. Curr. Opin. Biotechnol. 23, 227-235. doi: $10.1016 /$ j.copbio.2011.12.010

Fiorani, F., and Schurr, U. (2013). Future scenarios for plant phenotyping. Annu. Rev. Plant Biol. 64, 267-291. doi: 10.1146/annurev-arplant-050312-120137

Food and Agriculture Organization of the United Nations (2017). FAOSTAT Database. Rome: FAO. Available online at: http://faostat3.fao.org/

Frégeau-Reid, J. T., Choo, M. K., Ho, M., Martin, R. A., and Konishi, T. (2001). Comparisons of two-row and six-row barley for chemical composition using doubled-haploid lines. Crop Sci. 41, 1737-1743. doi: 10.2135/cropsci2001.1737

Furbank, R. T., and Tester, M. (2011). Phenomics-technologies to relieve the phenotyping bottleneck. Trends Plant Sci. 16, 635-644. doi: 10.1016/j.tplants.2011.09.005

Gamon, J. A., Peñuelas, J., and Field, C. B. (1992). A narrow-waveband spectral index that tracks diurnal changes in photosynthetic efficiency. Remote Sens. Environ. 41, 35-44. doi: 10.1016/0034-4257(92)90059-S

Gevaert, C. M., Suomalainen, J., Tang, J., and Kooistra, L. (2015). Generation of spectral-temporal response surfaces by combining multispectral satellite and hyperspectral UAV imagery for precision agriculture applications. IEEE J. Sel. Top. Appl. Earth Obs. Remote Sens. 8, 3140-3146. doi: 10.1109/JSTARS.2015.2406339

Gioia, T., Nagel, K. A., Beleggia, R., Fragasso, M., Ficco, D. B., Pieruschka, R., et al. (2015). Impact of domestication on the phenotypic architecture of durum wheat under contrasting nitrogen fertilization. J. Exp. Bot. 66, 5519-5530. doi: 10.1093/jxb/erv289

Gitelson, A. A., Merzlyak, M. N., and Chivkunova, O. B. (2001). Optical properties and nondestructive estimation of anthocyanin content in plant leaves. Photochem. Photobiol. 74, 38-45. doi: 10.1562/00318655(2001)074<0038:OPANEO>2.0.CO;2

Gitelson, A. A., Zur, Y., Chivkunova, O. B., and Merzlyak, M. N. (2002). Assessing carotenoid content in plant leaves with reflectance spectroscopy. Photochem. Photobiol. 75, 272-281. doi: 10.1562/0031-8655(2002)075<0272:ACCIPL>2.0. $\mathrm{CO} ; 2$

Gonzalez-Dugo, V., Hernandez, P., Solis, I., and Zarco-Tejada, P. J. (2015). Using high-resolution hyperspectral and thermal airborne imagery to assess physiological condition in the context of wheat phenotyping. Remote Sens. 7, 13586-13605. doi: 10.3390/rs71013586
Gorny, A., and Sodkiewicz, T. (2001). Genetic analysis of the nitrogen and phosphorus utilization efficiencies in mature spring barley plants. Plant Breed. 120, 129-132. doi: 10.1046/j.1439-0523.2001.00584.x

Haboudane, D., Miller, J. R., Tremblay, N., Zarco-Tejada, P. J., and Dextraze, L. (2002). Integrated narrow-band vegetation indices for prediction of crop chlorophyll content for application to precision agriculture. Remote Sens. Environ. 81, 416-426. doi: 10.1016/S0034-4257(02)00018-4

Hawkesford, M. J., and Lorence, A. (2017). Plant phenotyping: increasing throughput and precision at multiple scales. Funct. Plant Biol. 44, v-vii. doi: 10.1071/FPv44n1_FO

Hirel, B., Le Gouis, J., Ney, B., and Gallais, A. (2007). The challenge of improving nitrogen use efficiency in crop plants: towards a more central role for genetic variability and quantitative genetics within integrated approaches. J. Exp. Bot. 58, 2369-2387. doi: 10.1093/jxb/erm097

Hruska, R., Mitchell, J., Anderson, M., and Glenn, N. F. (2012). Radiometric and geometric analysis of hyperspectral imagery acquired from an unmanned aerial vehicle. Remote Sens. 4, 2736-2752. doi: 10.3390/rs4092736

Huete, A., Didan, K., Miura, T., Rodriguez, E. P., Gao, X., and Ferreira, L. G. (2002). Overview of the radiometric and biophysical performance of the MODIS vegetation indices. Remote Sens. Environ. 83, 195-213. doi: 10.1016/S0034-4257(02)00096-2

Huete, A. R. (1988). A soil-adjusted vegetation index (SAVI). Remote Sens. Environ. 25, 295-309. doi: 10.1016/0034-4257(88)90106-X

Hunt, E. R., Daughtry, C., Eitel, J. U., and Long, D. S. (2011). Remote sensing leaf chlorophyll content using a visible band index. Agron. J. 103, 1090-1099. doi: 10.2134/agronj2010.0395

Hunt, E. R., Doraiswamy, P. C., McMurtrey, J. E., Daughtry, C. S., Perry, E. M., and Akhmedov, B. (2013). A visible band index for remote sensing leaf chlorophyll content at the canopy scale. Int. J. Appl. Earth Obs. Geoinformation 21, 103-112. doi: 10.1016/j.jag.2012.07.020

Kefauver, S. C., El-Haddad, G., Vergara-Diaz, O., and Araus, J. L. (2015). "RGB picture vegetation indexes for High-Throughput Phenotyping Platforms (HTPPs)," in Proceedings of SPIE, Vol. 9637 (Toulouse), 96370J-1.

Kostadinova, S., Ganusheva, N., and Marcheva, M. (2016). Uptake and utilization efficiency of nitrogen and phosphorus in barley genotypes. J. Cent. Eur. Agric. 17, 346-355. doi: 10.5513/JCEA01/17.2.1714

Krapp, A. (2015). Plant nitrogen assimilation and its regulation: a complex puzzle with missing pieces. Curr. Opin. Plant Biol. 25, 115-122. doi: 10.1016/j.pbi.2015.05.010

Le Gouis, J. (1992). A comparison between two-and six-row winter barley genotypes for above-ground dry matter production and distribution. Agronomie 12, 163-171. doi: 10.1051/agro:19920204

Le Gouis, J., Delebarre, O., Beghin, D., Heumez, E., and Pluchard, P. (1999). Nitrogen uptake and utilisation efficiency of two-row and six-row winter barley cultivars grown at two N levels. Eur. J. Agron. 10, 73-79. doi: 10.1016/S.1161-0301(98)00055-0

Lü, P., Zhang, J. W., Jin, L. B., Liu, W., Dong, S. T., and Liu, P. (2012). Effects of nitrogen application stage on grain yield and nitrogen use efficiency of highyield summer maize. Plant Soil Environ. 58, 211-216. Available online at: http:// www.agriculturejournals.cz/publicFiles/65360.pdf

Medina, S., Vicente, R., Amador, A., and Araus, J. L. (2016). Interactive effects of elevated [CO2] and water stress on physiological traits and gene expression during vegetative growth in four durum wheat genotypes. Front. Plant Sci. 7:1738. doi: $10.3389 /$ fpls.2016.01738

Montes, J. M., Melchinger, A. E., and Reif, J. C. (2007). Novel throughput phenotyping platforms in plant genetic studies. Trends Plant Sci. 12, 433-436. doi: 10.1016/j.tplants.2007.08.006

Papastylianou, I. (1995). The effects of seed rate and nitrogen fertilization on yield and yield components of two-row barley. Eur. J. Agron. 4, 237-243. doi: 10.1016/S1161-0301(14)80050-6

Peñuelas, J., Filella, I., Biel, C., Serrano, L., and Savé, R. (1993). The reflectance at the 950-970 $\mathrm{nm}$ region as an indicator of plant water status. Int. J. Remote Sens. 14, 1887-1905. doi: 10.1080/01431169308954010

Pölönen, I., Saari, H., Kaivosoja, J., Honkavaara, E., and Pesonen, L. (2013). Hyperspectral imaging based biomass and nitrogen content estimations from light-weight UAV. Proc. SPIE 8887:88870J. doi: 10.1117/12.2028624

Postma, J. A., Schurr, U., and Fiorani, F. (2014). Dynamic root growth and architecture responses to limiting nutrient availability: linking 
physiological models and experimentation. Biotechnol. Adv. 32, 53-65. doi: 10.1016/j.biotechadv.2013.08.019

Rajala, A., Peltonen-Sainio, P., Jalli, M., Jauhiainen, L., Hannukkala, A., TenholaRoininen, T., et al. (2017). One century of Nordic barley breeding: nitrogen use efficiency, agronomic traits and genetic diversity. J. Agric. Sci. 155, 582-598. doi: 10.1017/S002185961600068X

Raun, W. R., and Johnson, G. V. (1999). Improving nitrogen use efficiency for cereal production. Agron. J. 91, 357-363. doi: 10.2134/agronj1999.00021962009100030001x

Rondeaux, G., Steven, M., and Baret, F. (1996). Optimization of soiladjusted vegetation indices. Remote Sens. Environ. 55, 95-107. doi: 10.1016/0034-4257(95)00186-7

Roujean, J. L., and Breon, F. M. (1995). Estimating PAR absorbed by vegetation from bidirectional reflectance measurements. Remote Sens. Environ. 51, 375-384. doi: 10.1016/0034-4257(94)00114-3

Rouse, J. W., Haas, R. H., Schell, J. A., Deering, D. W., and Harlan, J. C. (1974). Monitoring the Vernal Advancements and Retrogradation of Natural Vegetation. Final Report, NASA/GSFC, Greenbelt, MD.

Schindelin, J., Arganda-Carreras, I., Frise, E., Kaynig, V., Longair, M., Pietzsch, T., et al. (2012). Fiji: an open-source platform for biological-image analysis. Nat. Methods 9, 676-682. doi: 10.1038/nmeth.2019

Shannon, P., Markiel, A., Ozier, O., Baliga, N. S., Wang, J. T., Ramage, D., et al. (2003). Cytoscape: a software environment for integrated models of biomolecular interaction networks. Genome Res. 13, 2498-2504. doi: $10.1101 /$ gr.1239303

Suomalainen, J., Anders, N., Iqbal, S., Roerink, G., Franke, J., Wenting, P., et al. (2014). A lightweight hyperspectral mapping system and photogrammetric processing chain for unmanned aerial vehicles. Remote Sens. 6, 11013-11030. doi: $10.3390 /$ rs61111013

Van Sanford, D., and MacKown, C. (1987). Cultivar differences in nitrogen remobilization during grain fill in soft red winter wheat. Crop Sci. 27, 295-300. doi: 10.2135/cropsci1987.0011183X0027000 20035x

Vergara-Diaz, O., Kefauver, S. C., Elazab, A., Nieto-Taladriz, M. T., and Araus, J. L. (2015). Grain yield losses in yellow-rusted durum wheat estimated using digital and conventional parameters under field conditions. Crop J. 3, 200-210. doi: 10.1016/j.cj.2015.03.003

Vergara-Diaz, O., Zaman-Allah, M. A., Masuka, B., Hornero, A., Zarco-Tejada, P., Prasanna, B. M., et al. (2016). A novel remote sensing approach for prediction of maize yield under different conditions of nitrogen fertilization. Front. Plant Sci. 7:666. doi: 10.3389/fpls.2016.00666

Virlet, N., Sabermanesh, K., Sadeghi-Tehran, P., and Hawkesford, M. J. (2017). Field Scanalyzer: an automated robotic field phenotyping platform for detailed crop monitoring. Funct. Plant Biol. 44, 143-153. doi: 10.1071/FP16163

White, J. W., Andrade-Sanchez, P., Gore, M. A., Bronson, K. F., Coffelt, T. A., Conley, M. M., et al. (2012). Field-based phenomics for plant genetics research. Field Crops Res. 133, 101-112. doi: 10.1016/j.fcr.2012.04.003

Zaman-Allah, M., Vergara, O., Araus, J. L., Tarekegne, A., Magorokosho, C., Zarco-Tejada, P. J. et al. (2015). Unmanned aerial platform-based multispectral imaging for field phenotyping of maize. Plant Methods 11:35. doi: 10.1186/s13007-015-0078-2

Zarco-Tejada, P. J., González-Dugo, V., and Berni, J. A. (2012). Fluorescence, temperature and narrow-band indices acquired from a UAV platform for water stress detection using a micro-hyperspectral imager and a thermal camera. Remote Sens. Environ. 117, 322-337. doi: 10.1016/j.rse.2011.10.007

Zhou, B., Elazab, A., Bort, J., Vergara, O., Serret, M., and Araus, J. (2015). Lowcost assessment of wheat resistance to yellow rust through conventional RGB images. Comput. Electr. Agric. 116, 20-29. doi: 10.1016/j.compag.2015.05.017

Conflict of Interest Statement: The authors declare that the research was conducted in the absence of any commercial or financial relationships that could be construed as a potential conflict of interest.

Copyright (C) 2017 Kefauver, Vicente, Vergara-Díaz, Fernandez-Gallego, Kerfal, Lopez, Melichar, Serret Molins and Araus. This is an open-access article distributed under the terms of the Creative Commons Attribution License (CC BY). The use, distribution or reproduction in other forums is permitted, provided the original author(s) or licensor are credited and that the original publication in this journal is cited, in accordance with accepted academic practice. No use, distribution or reproduction is permitted which does not comply with these terms. 